\title{
RESENHA: DELALANDE, FRANÇOIS. A MÚSICA É UM JOGO DE CRIANÇA. Trad. Alessandra Cintra. SÃo Paulo: PEIRÓPOLIS, 2019. 240 P.
}

Book review: DELALANDE, François. A música é um jogo de criança. Trad. Alessandra Cintra. São Paulo: Peirópolis, 2019. 240 p.
Reseña: DELALANDE, François. A música é um jogo de criança. Trad. Alessandra Cintra. São Paulo: Peirópolis, 2019. 240 p.

\footnotetext{
Ana Paula Martos Simão Sposito Universidade Estadual de Maringá anapaulasimao1@gmail.com

Gladys Rosana Barbosa dos SANTOS Universidade Estadual de Maringá gladys.rosana@yahoo.com.br

Marcelo Onetta Fermiano Universidade Estadual de Maringá m.o.fermiano@gmail.com

CÁssia Virgínia Coelho de Souza Universidade Estadual de Maringá cvcsouza@uem.br
}

O livro A música é um jogo de criança, do pesquisador francês François Delalande, foi publicado originalmente em 1984 e traduzido para o português em 2019, por Alessandra Cintra, pela Editora Peirópolis. Teca Alencar de Brito prefacia esta edição apontando a relevância da obra que valoriza a relação natural da criança com a música. O livro é composto de diálogos organizados em dez capítulos, e, no final, dois capitulos de proposições para os educadores e uma discografia. Esse material foi elaborado a partir de entrevistas radiofônicas difundidas em 1976, pela rádio France Culture, entre Delalande e seus companheiros de pesquisa: Jack Vidal e Guy Reibel. O autor esclarece que os capítulos não precisam ser lidos em ordem sequencial, mas vale iniciar-se pelo primeiro, que apresenta a "pedagogia do despertar".

Delalande tornou-se membro do Groupe de Recherches Musicales (GRM) na França, a partir de seu envolvimento com o compositor Pierre Schaeffer e sua música concreta, bem como a música eletroacústica que emergia fortemente na época (Alarcon; Brito, 2019). Isso lhe deu subsídios para confirmar 
sua inquietação a respeito do ensino da música, muitas vezes, pautado em conceitos como o tonalismo e a música erudita. Suas pesquisas lhe mostraram que a música feita pela criança, as sonoridades que ela procura e pelas quais se interessa, estão muito mais próximas da música contemporânea que de qualquer outra. Como afirmam Urrutia Rasines e Diaz Gomez (2013, p. 12), essa música caracteriza-se por novidades em sua linguagem, com métodos, técnicas e linhas estéticas variados, assim como por uma prática que não se prende às regras musicais correntes.

Com rica bagagem de experimentações e pesquisas em campo, o autor dissemina a ideia de que é necessário um despertar para as sonoridades, principalmente no que diz respeito à criança, desde o seu nascimento.

No primeiro diálogo, "Qual música, qual pedagogia?”, Delalande expõe sua concepção de ensino musical em direção contrária ao que, normalmente, é difundido. Ele distingue a decorrência de um método ativo para uma concepção de prática criativa, de busca pela motivação da criança que lhe dá liberdade para atos de explorar, fazer, criar, sendo necessário, para tanto, suscitar uma pedagogia de "condutas musicais".

No segundo diálogo, "A música é um jogo de criança”, o pesquisador apresenta sua compreensão de jogo dentro da música para além de um preparo que desperta o interesse da criança; "ele é a própria música". Baseado nos estágios do desenvolvimento infantil de Piaget, Delalande considera que a música se faz presente na vida da criança por meio dos jogos sensório-motor, simbólico e de regra.

Em "Uma arte do gesto", terceiro diálogo, o autor retrata a música como uma arte expressiva, concebendo que todo som é consequência de um movimento que, por sua vez, está relacionado à afetividade. No quarto diálogo, "O ritmo: duplo mal-entendido", Delalande explica que o conceito de ritmo varia entre as culturas e como ele é pensado na música contemporânea.

Apoiando-se em Schaeffer, fundamentado em uma fonética dos ruídos, o autor apresenta uma tabela de palavras, explicações e exemplos sonoros que descrevem a forma e a matéria do som, que intitula o quinto diálogo do livro, "Palavras para descrever os sons".

No sexto diálogo, “Quais instrumentos?”, Delalande reflete sobre os meios para que as crianças façam suas explorações com liberdade e tenham gosto pela descoberta. Ele sugere disponibilizar materiais que possam ser utilizados para a pesquisa de fontes e construção sonora lembrando que o que importa não é o valor que damos aos instrumentos, mas o atribuído pelas crianças em suas experiências.

Ao refletir em "Como educar a escuta?", o pesquisador manifesta a preocupação com a necessidade de se motivar a vontade de ouvir e fazer música na criança, para, então, se realizar apreciação. Nesse sétimo diálogo, ele afirma que não há escuta sem motivação. Para ser criativa é preciso não se ater aos aspectos formais, mas à escuta pessoal, tal como acontece na criação musical. 
No oitavo diálogo, "As partituras", o autor discorre sobre as diferenças entre a criação musical individual e coletiva lembrando que a partitura, quando necessária, deve cumprir a função de uma guia para a memória, isso para que não ocorra um empobrecimento da notação, uma vez que esta seria, por si só, uma redução das ideias.

O nono diálogo explica o caráter social de uma obra no Ocidente. Em "É necessário que se faça criar obras?" o autor lembra que a realização de uma obra é uma atração adicional ao trabalho pedagógico.

Delalande discute no décimo diálogo, "Construir a música", aspectos como ideia musical, variação, motivo, associação de ideias e cadeia sonora, estabelecendo esta última como "ponto de chegada" da construção musical.

"O despertar musical: pontos de referência", bem como o item posterior, "O sentido da forma", reúnem um total de vinte observações feitas com crianças, em pesquisas realizadas pelo autor, relatadas e discutidas por temas já abordados durante o livro. Finalizando a obra, em "Da música que fazemos àquela que ouvimos", encontramos uma discografia que o pesquisador define como propostas que se aproximam da música feita pela criança.

A obra de Delalande concebe uma série de princípios que se chocam com a realidade do ensino da música dita, pelo próprio autor, tradicional. Ao expor seus pensamentos de forma clara e exemplificada, e por vezes cômica e irônica, ele aprofunda reflexões e propõe uma mudança de olhar para o ensino da música movido pela conscientização do despertar para as sonoridades e sua relação com a criança. A leitura da obra é de valor substancial para educadores musicais, como também para profissionais da educação básica, e, de maneira geral, para aqueles que são responsáveis pela formação de crianças.

\section{REFERENCIAS}

ALARCON, Alessandra Cintra; BRITO, Teca Alencar de. François Delalande: a pedagogia do despertar musical. Literartes, São Paulo, v. 1, n. 10, p. 12-32, 2019. Disponivel em: http://www.revistas.usp.br/literartes / issue/view/10938/1673. Acesso em: 23 set. 2020.

URRUTIA RASINES, Ana, DÍAZ GOMEZ, Maravillas. Educación y música contemporánea: encuentros y desencuentros entre compositores y docentes. Revista da Abem, Londrina, v. 21, n. 30, jan./jun., p. 11-24, 2013. 
Ana Paula Martos Simão Sposito é graduada e especialista em Educação Musical pela Universidade Estadual de Maringá (UEM). Atua na rede de ensino do estado do Paraná como professora de arte. Desenvolve atividades voltadas para o canto coletivo e o ensino da música com crianças em escola fundamentada na pedagogia Montessori. É integrante do grupo de teatro Meu Clown, de Maringá (PR). https://orcid.org/0000-0001-8221-8625

Gladys Rosana Barbosa dos Santos é graduada em Música pela Universidade Estadual de Maringá (UEM) com especialização em Educação Musical. Foi professora de piano e disciplinas complementares no Centro de Educação Musical Solar do Som. Atualmente ministra aulas como professora particular de piano e órgão eletrônico. https://orcid.org/0000-0002-6707-0869

Marcelo Onetta Fermiano é professor de música e violinista. Graduado em Licenciatura em Letras, com habilitação em Língua Portuguesa e Inglesa, pela Universidade Tecnológica Federal do Paraná (UTFPR) - campus Pato Branco. Possui bacharelado em Música pela Universidade Estadual de Maringá (UEM) com habilitação em Violino. Especialista em Educação Musical pelo Centro Universitário Claretiano - Batatais (SP). Atualmente, é mestrando no Programa de Pós-Graduação em Música (PMU) da Universidade Estadual de Maringá (UEM). Atua como instrutor de violino no Programa Arte Cidadã da Secretaria de Cultura de Chapecó (SC). Na área pedagógica desenvolve pesquisas relacionadas à criação e aperfeiçoamento de materiais didáticos para ensino coletivo e individual de violino. Enquanto violinista atua em atividades relacionadas à música de câmara, além de ser músico integrante da Orquestra Sinfônica de Chapecó. https://orcid.org/0000-0002-2677-7489

Cássia Virgínia Coelho de Souza é bacharel em Música com habilitação em Piano pela Academia de Música Lorenzo Fernandez do Rio de Janeiro, mestra em Música pela Universidade Federal do Rio Grande do Sul (UFRGS) e doutora em Música pela Universidade Federal da Bahia (UFBA). É professora da Universidade Estadual de Maringá (UEM) e professora aposentada da Universidade Federal de Mato Grosso (UFMT). Atua no curso de graduação em Música e no Programa de Pós-Graduação em Música, Mestrado da UEM. É membra fundadora da Associação Brasileira de Educação Musical (Abem), tendo sido editora da Revista da Abem no período 2011-2013. Sua ação na educação musical inclui os temas formação de professores, políticas educacionais e música como/na cultura. https://orcid.org/0000-0003-3557-8243 